Functional relationships evidenced and representations used by third graders within a functional approach to early algebra

\begin{abstract}
This study describes how 24 third-graders ( 8 -9 years old) relate and represent the relationships between variables when working with a functional thinking problem. This aspect contributes to providing insights about how elementary school students attend properties and relationships between covarying quantities rather than isolated computations. From a functional approach to early algebra, we describe written students' answers when working with a problem that involves a function, which includes questions for specific values and to generalize. Design research guidelines, specifically those set out for Classroom Teaching Experiment were followed. This study addresses the fourth and last Classroom Teaching Experiment session, which involved a function of the type $y=a x+b$ and students had not previously worked it. Students primarily evidenced correspondence relationship, using natural language and numerical representation to express this functional relationship. Our findings let us to state that: (a) although students were not used to working with these types of problems, eleven of them go beyond arithmetic computations, finding relationships that relate the variables; and (b) three students generalized using natural language as a useful vehicle, while there are other students who perceived the same regularity for different specific values but they are unable to represent generalization clearly.
\end{abstract}

\title{
Keywords
}

early algebra, generalization, functional relationships, functional thinking, representations.

\section{Para citar:}

Pinto, E., Cañadas, M. C. y Moreno, A. (en prensa). functional relationships evidenced and representations used by third graders within a functional approach to early algebra. International Journal of Science and Mathematics

Education https://doi.org/10.1007/s10763-021-10183-0 


\section{Introduction}

Algebraic thinking in elementary and middle grades (also known as early algebra) plays a crucial role in research on classroom algebra because it promotes the identification of mathematical relationships and structures, rather than isolated arithmetic and computational fluency, for instance (Cai \& Knuth, 2005). We adopt the idea of algebra and early algebra beyond the use of algebraic notation; we promote that students attend to properties and relationships between quantities explicitly and examining their generality (Kaput, 2008). Specifically, we focus on a functional approach to early algebra (Carraher \& Schliemann, 2007), in which function is the prime mathematical content.

Different studies have reported how 6-12 years old students identify, express, and generalize regularities in problems that involve functions (e.g., Blanton, Brizuela, Gardiner, Sawrey, \& Newman-Owens, 2015; Carraher \& Schliemann, 2007; Pinto \& Cañadas, 2021; Radford, 2018; Warren, Miller, \& Cooper, 2013). However, some topics have not been addressed in depth in the recent literature on a functional approach to early algebra. First, most of the studies focused on students' functional thinking report in general how they consider the relationships between variables in different problems (e.g., Carraher \& Schliemann, 2007; Panorkau \& Maloney, 2016). Nonetheless, these studies provide evidence of the need to describe the types of functional relationships, in students' answers, in more depth. Focusing on a deep description of functional relationships evidenced by students contributes to providing insights into how they work with two or more covarying quantities rather than isolated computations. 
Second, we are interested in describing how students express the relationships among variables beyond the four traditional types representations ${ }^{1}$ described in school algebra studies: natural language, graphical, tabular, and algebraic notation (Williams, 1993). This could help us to describe students' algebraic thinking and what types of representations are useful to them.

Third, this study is relevant in Spain. Mainly, the Spanish research conducted around functional thinking problems has focused primarily on the lower or upper grades of elementary school (e.g., Pinto \& Cañadas, 2018). As a consequence, there is a paucity of research addressing the intermediate grades of the elementary school on topics pivotal to working with functions, such as functional relationships and the types of representation used to express them.

Therefore, and considering the above reasons, our general research aim is to describe how third graders relate and represent the relationships between variables when working with a functional thinking problem.

\section{Conceptual Framework}

The framework that directs our study is based on Kaput's proposals (2008) for algebra and algebraic thinking in the early grades: generalization is the core aspect. Kaput indicates that "the heart of algebraic reasoning is comprised of complex symbolization processes that serve purposeful generalization and reasoning with generalizations" (p. 9). We focus on a functional approach to early algebra, which favoring the vision of arithmetic operations as functions and enabling students to explore the notion of variable as a variation between quantities (Blanton, Levi, Crites, \& Dougherty, 2011). Specifically, in this approach

\footnotetext{
${ }^{1}$ In this study, we focus on external representations to distinguish them from mental or internal ones. Therefore, every time we mention the term "representation" or "representations", we refer to external representations, made with pencil or paper, which are intentional, permanent, and have a spatial nature.
} 
generalizing functional relationships, as well as representing these relationships, are considered key elements. Smith (2008) points out that this approach (also known as functional thinking) is "focused on the relationship between two (or more) variables; specifically, the types of thoughts that go from specific relationships to generalizations of relationships" (p. 143). Therefore, we assume that functional thinking involves functional relationships, which may be generalized or not, and may be expressed through different types of representations.

\section{Functions and functional relationships}

The concept of function has evolved across time and has been addressed by different authors and perspectives (e.g., Romberg, Fennema, \& Carpenter, 1993; Sfard, 1991). We adopt the concept of function as "a correspondence between two nonempty sets that assigns to every element in the first set (the domain) exactly one element in the second set (codomain)" (Vinner \& Dreyfus, 1989, p. 357).

Different studies described students' difficulties when they formally work with functions across the post-elementary grades (e.g., Bush \& Karp, 2013). However, there is a growing interest in describing the work of elementary students with functions, given that this content is a way to introduce algebraic thinking in the early grades and it "opens the possibility that the difficulties exhibited by older students might stem from a lack of experiences with functional thinking in the elementary grades" (Stephens, Ellis, Blanton, \& Brizuela, 2017, p. 398). This study focuses on linear functions, specifically the type $f(x)=m x+b$ where $m$ and $b$ are constants, and variables $x$ and $y$ natural numbers. This type of function is deemed suitable for the age and type of work expected of elementary students (Carraher \& Schliemann, 2007).

Usually, in studies that address a functional approach to early algebra, functions are presented through contextualized problems (the problem used in this study is an example), in 
which questions are related to the relationships and rules between dependent and independent variables. From Smith's proposal $(2003,2008)$, functional relationships evidenced by students can be organized by how they consider the relationships between variables and there are three types: (a) recursive patterns, which involves attending to the variation or pattern within a sequence of values, so it describes the variation of values within a single variable; (b) correspondence, in which emphasis is on the relation between the corresponding pair of variables; and (c) covariation, which analyzes how two quantities covary and how the change between two values in the same variable affects in one produce change in the other. For instance, in this paper, we used the tiles problem to incite the students to relate the number of grey tiles (dependent variable) needed given a number of white tiles (independent variable). The three types of functional relationships are illustrated for the tiles problem in Figure 1.

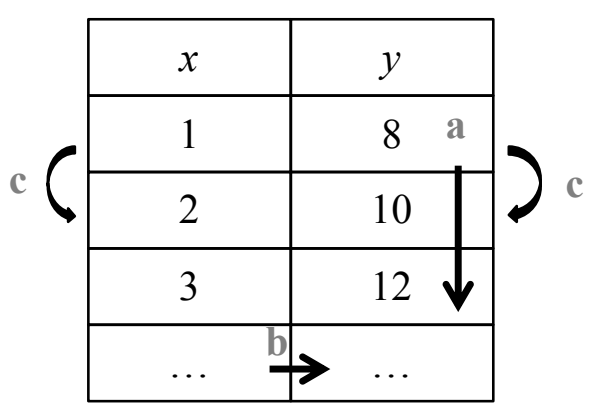

a. Recursive patterns. The value of the dependent variable is increasing from 2 to 2 .

b. Correspondence. The relationship between $x$ and $y$ is described verbally here, for instance, as twice $x$ plus six or algebraically as: $2 x+6 "$.

c. Covariation. When $x$ increases by $1, y$ increases by 2 .

Figure 1. Examples of functional relationships

Recursive patterns, correspondence, and covariation can be evidenced in students' responses when they are working on questions involving specific values and/or when generalizing the relationship (e.g., Pinto \& Cañadas, 2018).

A growing body of research differentiates between recursive patterns from correspondence and covariation relationships. Recursive patterns are centered on the values of a single variable and correspondence/covariation are part of functional thinking given "the 
emphasis on constructing a relationship between variables" (Smith, 2008, p. 146). As

Stephens et al. (2017) pointed out: "a focus of some of this recent research was the distinction between recursive and functional thinking and how to move students from the former to the latter" (p. 399). Considering recursive patterns, different studies reported two main trends: (a) it generates difficulties in students when trying to focus attention on the two variables (e.g., Carraher, Schliemann, \& Schwartz., 2008); and (b) early elementary graders have been shown to evolve from the ability to identify recurrent patterns to provide evidence of correspondence and covariation (e.g., Cañadas, Brizuela, \& Blanton, 2016). Recent studies (e.g. Blanton, et al., 2015; Morales, Cañadas, Brizuela, \& Gómez, 2018) showed that first graders (6-7 years old) working with problems that involve functions do not provide evidence of recursive patterns, tending to find correspondence relationships before finding recursive patterns. Other findings suggest that students' ability to identify a functional rule grows as they work with different specific values and it is more difficult to represent than to identify the functional relationship (Warren et al., 2013).

\section{Representations}

Representations are essential in building mathematical knowledge, as well as crucial vehicles for capturing mathematical ideas, which can be used to express a mathematical object, a concept, or a procedure constructed by students (Cai, 2005; Kaput, 1991). Specifically, representations are fundamental to functional thinking as they serve to: (a) represent mathematical ideas, forming an integral part of how students think about functions; (b) mediate between subjects and the functions and functional relationships, helping to structure and expand students' thinking; and (c) constitute a way of expressing relationships between variables, which if suitably chosen, it can unify possibly isolated ideas (Brizuela \& Earnest, 2008; Carpenter \& Franke, 2001). For instance, Figure 2 shows the different types of representations used by a first grader (6 years old) when working with a problem in which 
people's height when bare-headed was related to their height when wearing a 1-foot high hat, which is involving the function $y=x+1$.

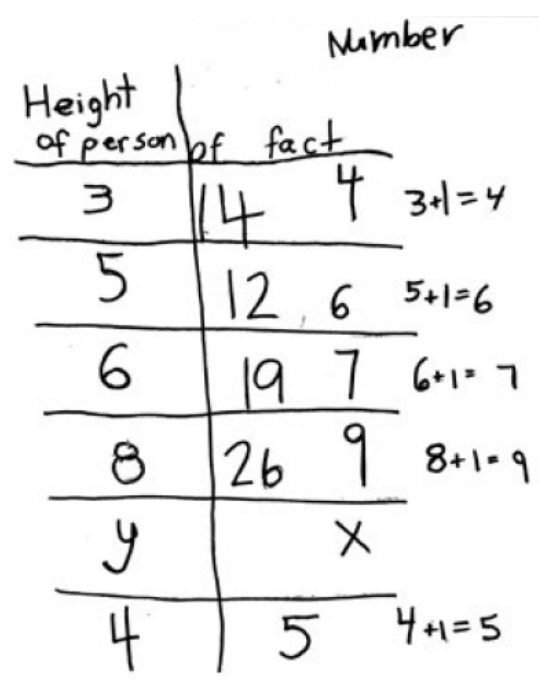

Figure 2. Example of functional relationship between specific corresponding values (Blanton et al., 2015, p. 531)

This problem was introduced to first graders (6 years old) in the context of a larger project focused on exploring how elementary students work on problems involving functions. In the height with a hat problem, the student organized specific heights of different people (see Figure 2). Specifically, this student evidenced a correspondence functional relationship for specific values in her response, recognizing the pattern that relates the dependent and independent variables. She initially arranged specific values in a table and subsequently, using a numerical representation, established the relationship between the two quantities (in the first row, for instance, writing $3+1$ to determine the person's height with the hat on). As this example shows, the student realized that different types of representation can be used to express a given functional relationship.

In recent research, Radford (2018) described the development of "symbolic algebraic thinking" from second to sixth graders (7-12 years old) based on problems involving functions. The author described different types of genuine algebraic symbolism while deeming "gesture, language, perception, and symbol use to account for non-conventional 
forms of signifying mathematical generality" (p. 12). Fourth graders (9-10 years old) were observed to initially generalize the relationship using natural language. One student, for instance, expressed the general rule using the word "always" (factual generalization). When asked to express the generalization using letters, he gave the general relationship as " $2 \times a=b+1=c "$. The two representations used by this student to generalize (natural language and algebraic notation) illustrate the importance of the notion of multiple representations, as discussed below.

Some researchers contend that multiple representations should be an essential part of school algebra, for it entails the application of the knowledge of operations, helping a deeper and fuller understanding of mathematics (Yerushalmy \& Schwartz, 1993). In particular, this study explores the relationship between two or more types of representations simultaneously used by students when solving problems involving linear functions. Within a functional thinking approach, multiple representations: (a) draws a connection between two types of representations, which become a tool for establishing a given relationship; (b) enables students to externalize and visualize different but complementary sides of an idea through meaning pathways; (c) creates an environment favorable to abstraction and comprehension of mathematical concepts, necessitating an understanding of how students use representation and inter-connections between types of representations; (d) and constitutes a topic scantily explored in elementary school grades (e.g. Brizuela \& Earnest, 2008; Confrey \& Smith, 1994). In a longitudinal study, Carraher and Schliemann (2007) analyzed students' understanding of certain features associated with functions on the grounds of their use of representations when working with problems involving linear functions. Figure 3 shows a fourth grader's answer to a problem relating the amount of pocket money two people have based on the functions $y=x+8$ and $y=3 x$ (Mike and Robin have some money. Mike has $\$ 8$ in his hand and the rest of his money is in his wallet. Robin has exactly three times as much 
money as Mike has in his wallet. How much money could there be in Mike's wallet? Who has more money?).

\begin{tabular}{|c|c|}
\hline Mike & Robin \\
\hline $\begin{array}{l}\text { Mike has } \$ 8 \text { in his } \\
\text { hand plus more } \\
\text { money in his } \\
\text { wallet. } \\
N 8 \\
N+\$ 8=\square \\
\begin{array}{l}\$ 8 \\
N 8\end{array}\end{array}$ & $\begin{array}{l}\text { Rabin has Nx3 } \\
\text { money } \\
\text { Robin has } 3 \text { times } \\
\text { as much moneyas } \\
\text { Mike has in his } \\
\text { wallet } \\
N \times 3=3 N\end{array}$ \\
\hline
\end{tabular}

Figure 3. Example of multiple representations (Carraher \& Schliemann, 2007, p. 693) Three types of representations (natural language, pictorial, and algebraic notation) converged in the student's response to calculate each person's pocket money shown in Figure 3. The three representations enabled him to generalize the relationship and infer, compare, and refine ideas (Brizuela \& Earnest, 2008).

\section{Research Questions}

In summary, we are interested in describing how third graders work with problems that involve covarying quantities. Considering the general research aim-to describe how third graders relate and represent the relationships between variables when working with a functional thinking problem — we address the following research questions: (a) What types of functional relationships are evidenced by third graders when working with a functional thinking problem? (b) What types of representations are used by third graders when expressing the relationship among variables involved in a given problem? In addressing these research questions, we analyze evidence from a specific session of a Classroom Teaching Experiment, in which students worked with a problem and answered different questions on a worksheet. 


\section{Method}

This study forms part of a broader research with Spanish students in the elementary grades (6-12 years old). Here the focus was on third-graders' answers to a functional thinking problem. Design research guidelines, specifically those set out for Classroom Teaching Experiment (CTE) were followed, in which the researcher acts actively as a teacher, studying the nature of the development of ideas in which students are included (Kelly \& Lesh, 2000). Specifically, we designed a four-session CTE in which a different problem was posed in each session; we focus on the fourth and last session. To summarize, Table 1 shows the problem contexts, some questions presented, and functions involved in each session. Some of them were selected from previous studies (the tiles problem was adapted from Küchemann, 1981, for instance) and others were designed by the research team.

Table 1. Problems and Functions used in each Session

\begin{tabular}{|c|c|c|}
\hline Session & Problem context & Function \\
\hline 1 & $\begin{array}{l}\text { María and Raúl are brother and sister. They live at La } \\
\text { Zubia. María is the elder. We know that María is } 5 \\
\text { years older than Raúl. } \\
\text { - When Raúl is } 7 \text { years old, how old is María? } \\
\text { How do you figure it out? } \\
\text { - When Raúl is } 15 \text { years old, how old is María? } \\
\text { - How do you figure it out? } \\
\text { When Raúl is } 80 \text { years old, how old is María? } \\
\text { How do you figure it out? }\end{array}$ & $y=x+5$ \\
\hline 2 and 3 & $\begin{array}{l}\text { Carlos wants to earn money selling T-shirts with the } \\
\text { school's emblem to go on a trip with the rest of the } \\
\text { class. He earns } 3 \text { euros for every T-shirt sold. } \\
\text { - The following table show some information } \\
\text { about the number of T-shirts sold by Carlos } \\
\text { and the money he has earned from them. Fill } \\
\text { in the gaps. }\end{array}$ & $y=3 x$ \\
\hline
\end{tabular}


Table 1. Problems and Functions used in each Session

\begin{tabular}{|c|c|c|c|c|}
\hline \multirow{6}{*}{$\begin{array}{l}\text { Session } \\
4\end{array}$} & \multicolumn{3}{|c|}{ Problem context } & Function \\
\hline & \multirow{4}{*}{\multicolumn{4}{|c|}{$\begin{array}{l}\text { A school wants to replace the floor in all its corridors, } \\
\text { where the tiles are severely damaged. Its board decides } \\
\text { to lay white and grey tiles on all the floors. All the tiles } \\
\text { are square and of the same size and are to be laid in the } \\
\text { following pattern: }\end{array}$}} \\
\hline & & & & \\
\hline & & & & \\
\hline & & & & \\
\hline & \multicolumn{4}{|c|}{$\begin{array}{l}\text { The school asks a company to replace the floors in all } \\
\text { the corridors. We want you to help the masons answer } \\
\text { some questions before they can start work. } \\
\text { - How many grey tiles do they need if a } \\
\text { corridor has eight white tiles? }\end{array}$} \\
\hline
\end{tabular}

Problems presented to students (see Table 1) were selected according to three criteria: (a) types of functions that would be adequate for the students' ages; (b) type of structure (additive and/or multiplicative) involved in each function; and (c) the kind of values involved in each problem. Additionally, we selected contexts that were familiar and attractive to students and ordered the problems from less to more difficulties according to results in previous studies (e.g., Blanton et al., 2015). Students were asked to answer several questions in connection with the problems in Table 1. All the four sessions included questions that involve specific values and the general relationships between variables, across different formats: (a) true and false item; (b) open-ended questions; (c) create/complete function tables, for instance (for more information, see Ayala-Altamirano and Molina, 2019). All questions were designed based on the inductive reasoning model described by Cañadas and Castro (2007), which involve questions that include specific values and generalization. Three researchers were present during the CTE: one was the teacher-researcher, the other the support researcher, and the third acted as the video camera operator. The usual mathematics teacher, by her own decision, participated as an observer.

\section{Data selection}


This paper reports the findings from the last CTE session. Three main reasons motivate the interest in the last session. First, the tiles problem involved a function of type $f(x)=m x+b$ and it involves a pictorial representation in the statement, which the students had not previously worked in the CTE. While students had not been formally introduced to multiplication and given the exploratory nature of the study, we conjectured that these could have addressed questions through repeated additions. Second, this session was the last one and the students were more familiar with working with functional thinking problems and with the research team. Third, this problem was worked with fifth-grade students, which will allow us to make comparisons in the future.

\section{Participants}

The participants were 24 third-grade students (8-9 years old) who attended a Spanish school. The school was intentionally chosen because of its interest in collaborating. The students had not been introduced to problems involving functional relationships prior to the sessions. They had been taught to add and subtract, count one by one, two by two, five by five and ten by ten. Students had been introduced to multiplication as repeated addition and had not yet explored multiplication tables or multiplication properties. None required an adapted curriculum.

\section{Data collection and instrument}

Session 4, the one addressed here, consisted of three parts. First, the teacher-researcher introduced the tiles problem and asked the students questions to ensure they had understood it (see Table 1). Students then individually answered the worksheet that included the five questions shown in Figure 4. 
Q1. How many grey tiles do they need if a corridor has five white tiles?

Q2. Some corridors are longer than others. Therefore, the masons need different numbers of tiles for each corridor. How many grey tiles do they need for a corridor with eight white tiles?

Q3. How many grey tiles do they need for a corridor with 10 white tiles?

Q4. How many grey tiles do they need for a corridor with 100 white tiles?

Q5. The masons always lay the white tiles first. How can they figure out how many grey tiles tiles they need if they've already laid the white tiles?

Figure 4. The tiles problem

The first three questions (Q1-Q3) involved specific values with numbers under 100, while the value in the specific value in Q4 was 100. Question 5 (Q5) asked for generalization. Students were allowed to use manipulatives representations, namely white and grey paper squares, to represent the two types of tiles.

In the last part of the session, the group pooled its experience on the work performed, led by the teacher-researcher who asked questions and encouraged the students to explain their answers.

Information was gathered from three sources: (a) the video recordings of the session; (b) the researchers' notes; and (c) the students' answers on their individual worksheets. The data analyzed in this paper were the students' CTE worksheets because we have answers from all the students (and the videos recording only contain the oral answers of some students). Specifically, in each student's worksheet is possible to identify ways to relate quantities as well as representations used to express their ideas.

\section{Data and Analysis Categories}

Data analysis involve a concept-driven development, and was performed sequentially (Kuckartz, 2019; Schreier, 2012). First, we established the procedure for the analysis categories derived from the literature (Blanton et al., 2011; Brizuela \& Earnest, 2008; Carraher \& Schliemann, 2008, Smith, 2003, 2008; Stephens et al., 2017). We adopted two 
major categories: (a) functional relationships, which involves identifying whether or not students' responses provided evidence of functional relationships, and (b) representations, which allow us to describe how students expressed the relationships between variables.

Second, and with the aim of delving into the types of functional relationships and representations evidenced in students' responses, each category was divided into the subcategories proposed by Smith $(2003,2008)$ and Carraher and Schliemann (2007). Table 2 summarizes the categories and subcategories used to analyze each student's responses (from Q1 to Q5).

Table 2. Analysis Categories

\begin{tabular}{ll}
\hline \multicolumn{1}{c}{ Category } & \multicolumn{1}{c}{ Sub-category } \\
\hline 1.1. Functional & 1.1.1. Recursive patterns, specific values. \\
relationships: provide & 1.1.2. Recursive patterns, generalizing. \\
evidence of a functional & 1.1.3. Correspondence, specific values. \\
relationship. & 1.1.4. Correspondence, generalizing. \\
& 1.1.5. Covariation, specific values. \\
& 1.1.6. Covariation, generalizing. \\
1.2. Functional & 1.2.1. Student only answered the question. \\
relationships: not provided & 1.2.2. Student repeated the problem wording. \\
evidence of a functional & 1.2.3. Student furnished or alluded to pictorial \\
relationship. & representations, but does not provide information on the \\
& relationship. \\
& 1.2.4. Student performed arithmetic computations with no \\
& clear meaning. \\
1.2.5. Student did not answer the question. & 2.1. Natural language. \\
2. Representation. & 2.2. Manipulative. \\
& 2.3. Pictorial. \\
2.5. Algebraic notation. & 2.6. Tabular. \\
2.7. Multiple representations*
\end{tabular}

Note: $*=$ all the possible combinations of more than one of the types of representations listed

As Table 2 shows, students could provide evidence of functional relationships when they were asked for specific values or when generalizing. Given the problem type, students were deemed to have evidenced a functional relationship when: (a) a regularity was evidenced in at least two of the first three questions (Q1-Q3); (b) a functional relationship was identified in 
Q4 and the preceding questions; or (c) when a functional relationship was evidenced in the answer to Q5. Those criteria were adopted to ensure that functional relationships would not be identified on the grounds of the answer to a single question that might have been found arithmetically. To illustrate how we identified functional relationships and representations in students' answers, Figure 5 shows S9's answers to different questions of the tile problem.

\begin{tabular}{|c|c|}
\hline $\begin{array}{l}\text { Q2. (Find the number of grey tiles if } \\
\text { there are } 8 \text { white tiles) }\end{array}$ & $8+8=16 \quad 16+3+3=22$ \\
\hline $\begin{array}{l}\text { Q3. (Find the number of grey tiles if } \\
\text { there are } 10 \text { white tiles) }\end{array}$ & $10+10+3+3=26$ \\
\hline $\begin{array}{l}\text { Q5. (Find the number of grey tiles } \\
\text { given any number of white tiles) }\end{array}$ & "You add 6 to twice the number of white tiles" \\
\hline
\end{tabular}

Figure 5. S9's answers to $Q 2, Q 3$, and $Q 5$

In S9' responses, we consider correspondence because a rule is constructed to determine the unique value of any given value $(x)$, thus creating a correspondence between $x$ and $y$. For instance, in responses to Q2 and Q3, the student built a correspondence between the $x$-values (e.g., $x$ ) and the $y$-values (e.g., $x+x+3+3$ ). Also, this student used a numerical representation to relate the variables involved in specific values and the natural language to generalize (Q5).

We consider the students as the unit of analysis, analyzing their written answers to the five questions presented on the worksheet. Each student's answer was coded in two phases. First, the corresponding author coded all written answers considering both categories. Then, we contrasted these codes with the other two authors. The results reported in this paper are related to all students' answers to the worksheet.

\section{Results}

Broadly speaking, all students $(n=24)$ provided responses to the first three questions, which involved specific values equal to or lower than 10. Nineteen students answered Q4 (100 
white tiles), and 16 students answered Q5 (generalization). Students were provided all the time they needed.

In the following, we describe the finding related to functional relationships identified in student's responses as well as mathematical representations used by them to express these relationships.

\section{Functional relationships}

We analyze students' work to the tiles problem, identifying functional relationships (recursive patterns, correspondence, and/or covariation) in their responses. To summarize, Table 3 presents those students who did not provide evidence of functional relationships in their responses and those who did. In students that provide evidence of functional relationships, we distinguishing between students' responses when working with specific values or the generalization of this functional relationship.

Table 3. Functional Relationships Identified in Students' Responses

\begin{tabular}{|c|c|c|c|c|}
\hline \multirow{3}{*}{$\begin{array}{l}\text { Did not provide } \\
\text { evidence of } \\
\text { functional } \\
\text { relationship }\end{array}$} & \multicolumn{4}{|c|}{ Provided evidence of functional relationship } \\
\hline & \multicolumn{2}{|c|}{ Correspondence } & \multicolumn{2}{|c|}{ Covariation } \\
\hline & $\begin{array}{l}\text { Specific } \\
\text { values }\end{array}$ & Generalization & $\begin{array}{c}\text { Specific } \\
\text { values }\end{array}$ & Generalization \\
\hline $\begin{array}{l}\text { S1, S2, S4, S7, } \\
\text { S8, S10, S15, } \\
\text { S16, S17, S18, } \\
\text { S20, S21, S23 }\end{array}$ & $\begin{array}{c}\text { S3, S5, S6, } \\
\text { S9, S11, } \\
\text { S13, S14, } \\
\text { S19, S22, } \\
\text { S24 }\end{array}$ & S9, S11, S22 & $\mathrm{S} 3, \mathrm{~S} 12$ & - \\
\hline
\end{tabular}

As the data in Table 3 show, thirteen of the 24 third graders did not provide evidence of functional relationships in their written responses. S17's answer to Q1 (How many grey tiles do they need for a floor with five white tiles?), for example, was: " 16 tiles because I counted them on the drawing". In her answer, S17 referred to the pictorial representation included in the problem and her response do not provide evidence of a functional relationship.

In contrast, from the 11 students in whose answers functional relationships were identified, nine provided evidence of correspondence only (S5, S6, S9, S11, S13, S14, S19, 
S22, and S24) and three of these students generalized (S9, S11, and S22). One student provided evidence of correspondence and covariation (S3), while another student only provided evidence of covariation in the answers related to specific values (S12). Recursive patterns were not identified in students' responses.

To provide examples of each functional relationships identified, in the following sections we present some examples that illustrate ways in which students related variables.

Evidences of correspondence. Broadly speaking, ten students provided evidence of this relationship, either when working with specific values or when generalizing. Table 4 presents the students' answers in which we identified this relationship.

\section{Table 4. Correspondence Identified in each Students' Answers}

\begin{tabular}{llllll}
\hline Student & \multicolumn{5}{c}{ Questions } \\
\cline { 2 - 6 } & Q1 & Q2 & Q3 & Q4 & Q5 \\
\hline S3 & & & $\checkmark$ & $\checkmark$ & $\checkmark$ \\
S5 & $\checkmark$ & $\checkmark$ & $\checkmark$ & $\checkmark$ & $\checkmark$ \\
S6 & $\checkmark$ & $\checkmark$ & $\checkmark$ & $\checkmark$ & $\checkmark *$ \\
S9 & & $\checkmark$ & $\checkmark$ & $\checkmark$ & $\checkmark *$ \\
S11 & $\checkmark$ & $\checkmark$ & $\checkmark$ & $\checkmark$ & \\
S13 & & $\checkmark$ & $\checkmark$ & & \\
S14 & & $\checkmark$ & $\checkmark$ & $\checkmark$ & $\checkmark *$ \\
S19 & $\checkmark$ & & $\checkmark$ & $\checkmark$ & $\checkmark$ \\
S22 & & $\checkmark$ & & \\
S24 & & & & & \\
\hline
\end{tabular}

Note. $*$ = generalization.

As Table 4 shows, of the 10 students who evidenced a correspondence, seven did so for specific values only. In one student, S19, we identified correspondence only for questions involving amounts of under $100(\mathrm{Q} 1$ and Q3); another, S3, only for the question involving the specific value of 100 tiles (Q4); and five for specific values involving amounts less than or equal to 100 (Q1-Q4).

S5's answers to some questions, deemed representative for the way in which she provides evidence of the correspondence relationship between the variables in specific values, are shown in Figure 6. 


\begin{tabular}{l}
$\begin{array}{l}\text { Q1. (Find the number of grey tiles if } \\
\text { there are } 5 \text { white tiles) }\end{array}$ \\
$\begin{array}{l}\text { Q2. (Find the number of grey tiles if } \\
\text { there are } 8 \text { white tiles) }\end{array}$ \\
$\begin{array}{l}\text { Q3. (Find the number of grey tiles if } \\
\text { there are } 10 \text { white tiles) }\end{array}$ \\
$\begin{array}{l}\text { Q4. (Find the number of grey tiles if } \\
\text { there are } 100 \text { white tiles) }\end{array}$ \\
\hline
\end{tabular}

Figure 6. S5's answers to Q1-Q4

In her answer, S5's (see Figure 6) focused on the number of grey tiles given the number of white tiles. In all four replies, she built a correspondence between the $x$-values $(5,8,10$, and $100)$ and the $y$-values $(16,22,26$, and 206). S5 answered all the questions following the same "closed form rule" to describe a relation between quantities (Confrey \& Smith, 1994), adding to the number of tiles on the left and right sides $(3+3)$ the number of top and bottom grey tiles, which varied from one question to the next. Thus, S5 provided evidence of a rule constructed to determine the unique value of any given value $(x)$, creating a correspondence between $x$ and $y$.

All three students who generalized the correspondence did answer to Q5- when we explicitly ask for this relationship — and also provide evidence of correspondence for all the specific values (Q1-Q4). Two students provide evidence of generalization only considering the constant in the function; they identified the number of grey tiles that, regardless of the number of white tiles, are always the same: three on the right side and three on the left (six in total). For instance, S22 answered to Q5 writing “adding 6". Student S9, in turn, generalized all the elements involved in the function (relating the dependent and independent variables). Figure 5 shows the functional relationships identified in S9's answers. This student's answers provided evidence, through an arithmetic computation, of the relation between corresponding pair of variables in Q2 and Q3 in these answers. The student built a correspondence between 
the $x$-values ( 8 and 10) and the $y$-values (22 and 26). In other words, the student added twice the number of top and bottom grey tiles and add three right and three left tiles. Then, when he answered to Q5, he simplified the expression adding six (instead of 3+3) to "twice the number of white tiles", capturing the general rule for any number of white tiles. Therefore, the student built a correspondence between the $x$-values $(x)$ and the $y$-values $(2 x+6)$.

Evidences of covariation. We identified covariation in two students' answer and neither generalized that relationship. One student, S12, provide evidence of covariation in his responses to Q2, Q3, and Q4. Figure 7 reproduces the answers furnished by the student.

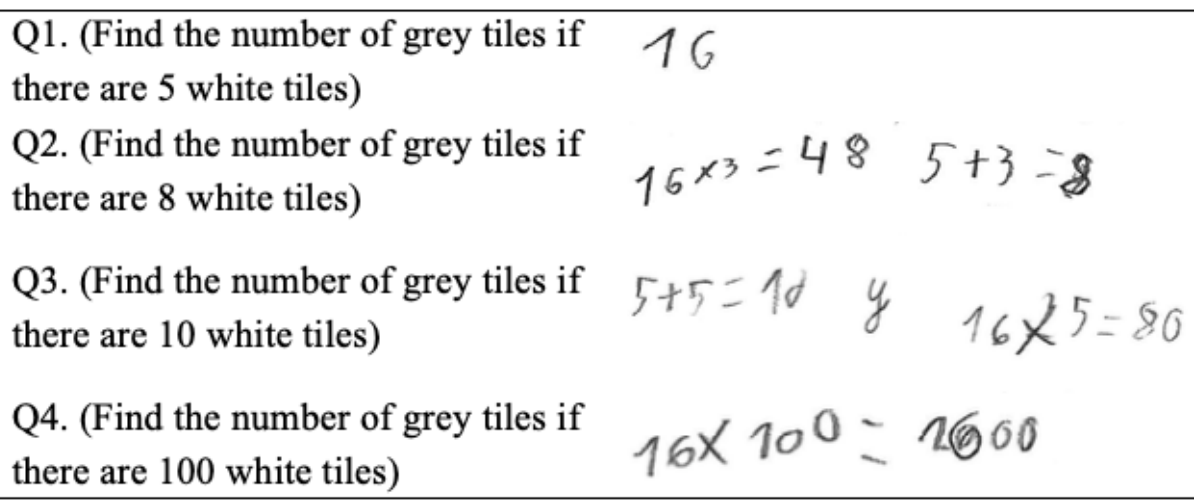

Figure 7. S12's answers to Q1-Q4

Note: $y$ means "and" in Spanish

S12's answers show that he realized that the change in value in one variable affects the value of the other variable. To illustrate the covariation identified in student's answers, Figure 8 illustrate the way in which he related the independent variable ( $x$, number of white tiles) and the dependent (y, number of grey tiles) in two questions: Q2 and Q3.

(a) Student's answer to Q2

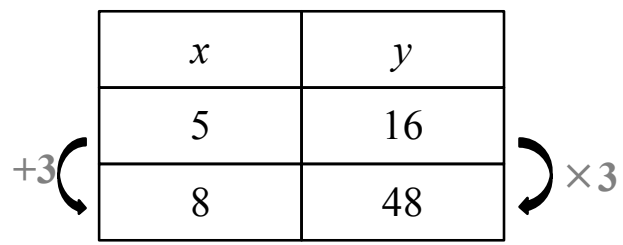

(b) Student's answer to Q3

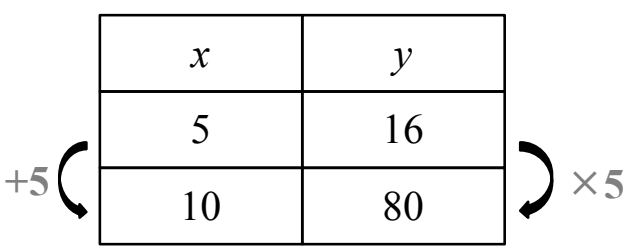

Figure 8. Example of covariation in S12's answers 
In (a), he identified the difference between five and eight (three), which he then multiplied times the number of grey tiles needed for five white tiles, i.e., he applied different arithmetic operations to the dependent and independent variables. In others words, he noticed that when $x$ increases by $3, y$ increases three times. Then, in (b), he identified that the change between 5 and 10 is adding five, thus, he multiplicate the number of grey tiles to five white tiles (16) by five, resulting 80 . Here, he noticed that when $x$ increases by $5, y$ increases 5 times.

In S3's responses, we identified covariation in Q3, while he provided evidence of correspondence in his responses to Q4 and Q5. He was the sole student in which we identified both functional relationships, although he did so in answers to different questions. The answers that attested to her evidence of covariation are reproduced in Figure 9.

$\begin{aligned} & \text { Q2. (Find the number of grey tiles if } \\ & \text { there are } 8 \text { white tiles) } \\ & \text { them" }\end{aligned}$
$\begin{array}{ll}\text { Q3. (Find the number of grey tiles if } \\ \text { there are } 10 \text { white tiles) }\end{array}$
$\begin{aligned} & 22 . \text { "if for } 8 \text { [referring to Q2] you need } \\ & 20+2=22 "\end{aligned}$

Figure 9. S3's answers to Q3

S3's answers (Figure 9) revealed that to answer Q2, she used the manipulative representations (white and grey paper squares to represent the two types of tiles) to visualize the eight white tile question (20, in her count). To reply to Q3 (find the number of grey tiles if there are 10 white tiles) she established a covariation relationship, building on the result of the preceding question to define a procedure (add 2) to find the answer. Here the student used the variation between the number of white tiles $(10-8=2)$ to calculate the number of grey tiles, concluding that two more would also be needed. Focusing on the simultaneous change in the two variables, she realized that any variation in the value of the independent variable entailed a variation in the value of the dependent variable.

\section{Representations}


Considering all students in which we identified functional relationships, Table 5 shows the types of representations used by them in different questions. Given correspondence is the most frequent functional relationship, Table 5 shows the representations used by students who evidenced this relationship. The shading indicates the representation used by the two students in which we identified covariation.

\begin{tabular}{|c|c|c|c|c|c|}
\hline \multirow[t]{2}{*}{ Student } & \multicolumn{5}{|c|}{ Questions } \\
\hline & Q1 & Q2 & Q3 & Q4 & Q5 \\
\hline S3 & & $\mathrm{M} ; \mathrm{NL}$ & $\mathrm{NL} ; \mathrm{N}$ & $\mathrm{N}$ & $\mathrm{NL}$ \\
\hline S5 & $\mathrm{N}$ & $\mathrm{N}$ & $\mathrm{N}$ & $\mathrm{N}$ & \\
\hline S6 & NL & $\mathrm{NL}$ & $\mathrm{N}$ & $\mathrm{N}$ & NL \\
\hline S9 & & $\mathrm{N}$ & $\mathrm{N}$ & $\mathrm{N}$ & NL* \\
\hline S11 & NL & $\mathrm{NL} ; \mathrm{N}$ & & $\mathrm{NL} ; \mathrm{N}$ & $\mathrm{NL} ; \mathrm{N}^{*}$ \\
\hline $\mathrm{S} 12$ & & $\mathrm{NL} ; \mathrm{N}$ & $\mathrm{N}$ & $\mathrm{N}$ & \\
\hline $\mathrm{S} 13$ & & & NL & NL & \\
\hline $\mathrm{S} 14$ & & NL & $\mathrm{NL} ; \mathrm{N}$ & $\mathrm{N}$ & \\
\hline S19 & $\mathrm{P} ; \mathrm{N}$ & & $\mathrm{NL} ; \mathrm{N}$ & & \\
\hline $\mathrm{S} 22$ & $\mathrm{~N}$ & $\mathrm{~N}$ & $\mathrm{~N}$ & $\mathrm{~N}$ & NL* \\
\hline S24 & & & $\mathrm{NL} ; \mathrm{N}$ & $\mathrm{N}$ & $\mathrm{P}$ \\
\hline
\end{tabular}

Note. $\mathrm{NL}=$ natural language; $\mathrm{N}=$ numerical; $\mathrm{P}=$ pictorial; $\mathrm{M}=$ manipulative. $*$ = generalization.

As Table 5 shows, students tended to express both functional relationships numerically or using natural language. Two students used pictorial representation (S19 and S24) and one student (S3) used manipulative (S3). Specifically, correspondence relationships were represented numerically and using natural language to Q1 and Q2 (5 and 8 white tiles, respectively). In their responses to Q3 and Q4 (10 and 100 white tiles, respectively), students used primarily numerical representation, using arithmetical computations to connect both variables. In responses to Q5, students mainly answered the question through natural language, which was the same type of representation used by the three students who generalized. Covariation relationships were described numerically and through natural language. 
Six students exhibited multiple representations, all mainly related to correspondence. Multiple representations identified here were primarily combinations of natural language and numerical, and to a lesser extent, pictorial and numerical representation. None of the students' answers was indicative of the presence of three (or more) types of representations in a single answer. By way of example, S24's answer to Q3 contained two types of representations, as illustrated in Figure 10.

\begin{tabular}{|ll|}
\hline $\begin{array}{l}\text { Q3. (Find the number of grey tiles if } \\
\text { there are } 10 \text { white tiles) }\end{array}$ & $\begin{array}{l}26 . \text { There are } 10 \text { white tiles, three grey tiles on } \\
\text { each side and } 10 \text { on the top and } 10 \text { on the bottom } \\
10+10=23+3=26\end{array}$ \\
\hline
\end{tabular}

Figure 10. S24's answer to Q3

This figure shows that both the natural language and numerical representation furnished information and while their meanings were independent, they were both needed to reply fully to the question.

In the same vein, S19 combined pictorial and numerical representation, which must be analyzed together for them to make sense, as shown in Figure 11.

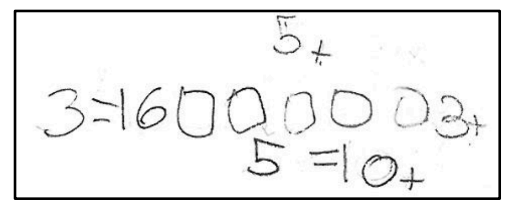

Figure 11. S19's answers to Q1

In the answer to Q1 exemplified in Figure 11, the student used a pictorial arrangement to represent the number of white tiles and numbers to represent the number of top, bottom, left and right-side grey tiles. In light of the joint use of pictorial and numerical representation, this was deemed to constitute multiple representations.

\section{Discussion}

The objective of the study reported here was to describe how third graders relate and represent the relationships between variables when working with a functional thinking 
problem. The findings reported add to a growing body of research in early algebra that has shown that it is possible to explore how elementary school students work with problems that involve functions. Specifically, third graders provided evidences of sophisticated ways to relate variables (and generalize), even when they have not been worked this type of problems in traditional mathematics classrooms.

In students' responses to the tiles problem, there is a decrease in the number of responses from Q1 to Q5 (from particular cases to generalization). That circumstance suggests that the difference may have been determined by the type of question. We interpret that the work with Q5 implied to attend the relationship between variables for any values, which can be a challenge for them since they were not used to working with these types of questions and generalization is not simple, requiring time in students' reasoning (Dienes, 1961).

The study was intented to respond the following research questions: (a) What types of functional relationships are evidenced by third graders when working with a functional thinking problem? and (b) What types of representations are used by third graders when expressing the relationship among variables involved in a given problem? In terms of the first research question, thirteen of the 24 students did not provide evidences of functional relationships. The absence of functional relationships identified in these students could be explained by two reasons. First — and related to the results of other studies with elementary students (e.g., Blanton et al., 2015) — these students could be focused on the particularities of arithmetic calculation. Second, the worksheets may not capture all the relationships students thought. However, eleven students did so. Similar to findings reported in other studies (e.g., Pinto \& Cañadas, 2018) recursive patterns were not identified in students' responses, which 
could be explained because students did not work with consecutive specific values (according to questions involved in the problem).

The predominance of correspondence helps us to describe features of students' functional thinking; they tend to focus on the construction of a rule to determine the unique value of any given value (x), thus creating a correspondence between $\mathrm{x}$ and $\mathrm{y}$ (Ayalon, Watson, \& Lerman, 2015). Most of the students (S5, for instance, in Figure 5) provide evidences of the same correspondence rule working with specific values (no generalizing) could be reflect that this student perceived a regularity that extended to different specific values but, when asked directly about generalization, he was not able to represent it. This result could be related to the ideas of some authors, who point out that young students are naturally predisposed to perceiving regularities and generalizing, even when they are unable to represent these processes clearly (Mason, 1996). On the other hand, two students provided evidence of covariation. It could be explained in terms of this relationship is more difficult for students. Students who provided evidence of functional relationships tended to focus on the corresponding pair of values but not connect or relate how the change between two values on the same variables affects in one produce change in the other.

In terms of the second research question, numerical and natural language are the representations most used by students to express the relationship between variables. The use of numerical representation makes sense, since the students were asked about specific values and not general ones. This could be an indicative element of the type of representation traditionally presented in the mathematics classes to these students: the numerical one. The use of natural language to relate variables, and as Radford (2018) pointed out, is a useful vehicle to express general rules as well as it is a useful scaffold for the development of a more symbolic representations. In addition, the presence of multiple representations in student responses is relevant. Multiple representations provide insight into how students 
reason algebraically, one of today's research challenges and it should form an essential part of algebra instruction (Wilkie, 2016). The existence of multiple representations in some students' answers (see Figure 10, for instance) provides grounds for analyzing how they use two types of representations jointly to predict, compare, and understand one relative to the other to better understand the mathematical idea underlying the problem (Brizuela \& Earnest, 2008).

\section{Conclusions}

Considering a functional approach to early algebra, this study provides evidence of how a group of third graders focuses on mathematical relationships and structures more than isolated computations. An increasing number of studies have reported the work of elementary students with functional thinking problems (e.g., Blanton, et al., 2015; Carraher \& Schliemann, 2007; Pinto \& Cañadas, 2018). However, this study contributes to deepen and provide detailed evidence of how students relate and express relationships between variables. The approach considered in this study illuminates a way to describe how students build sophisticated (and even generalized) mathematical relationships.

The data presented here reflects clearly our perspective about algebraic thinking; it could take place in the absence of algebraic notation and provides students with tools that allow a high degree of certain types of generality (Lins \& Kaput, 2004) so that they can explore, establish, and build general mathematical relationships. Representations used by these students to express the relationships between variables beyond the four traditional types representations described in school algebra studies: natural language, graphical, tabular, and algebraic notation. This helps us to describe students' algebraic thinking and what types of representations are useful to them, considering that representations used in daily activities 
(natural language and numerical) could act as a useful scaffold for more symbolic representations.

The tiles problem allows illustrating how students relate and generalize relationships involving dependent and independent variables. Three main implications for teaching arise from our study. First, consider problems that explicit and involve the relationship between two variables (including geometric patterns) reinforces the idea of some authors (e.g., Mason, Graham, Pimm, \& Gowar, 1985) who emphasize that these types of activities are a way to introduce students to algebra, since they are recommended due to their dynamic representation with the variables. Second, and considering the main representations used by students, natural language - which is the same type of representation introduced in the problems - could be indicative of the importance of introducing and teaching different representations to help students to communicate their mathematical ideas in different ways. In addition, numerical representation is a useful bridge to find relationships more than isolated computations; this type of representation provides the opportunity to enrich the students' mathematical learning. Third, and as other authors point out (e.g., Rivera, 2013), the use of visual pattern in functional thinking problems is an important path which helps students in their first generalizations, favoring the interaction between visual, numerical, and general relationships.

In closing, we know that our results can not be generalized because we analyze one specific session in a specific context. However, this study can help to: (a) understand how elementary school students work and generalize a problem that involved the function of the type $y=a x+b$, and (b) recognize that students can generalize, even when they were not used to doing it in their mathematics lessons. In addition, we know that neither algebraic thinking in general nor functional thinking, in particular, is developed intuitively or naturally with today's curricula (Kieran et al., 2016), as is the case of Spain, where this study is carried out. 
Nonetheless, three of the student participants in the teaching experiment generalized the relationship between the dependent and independent variables. Further research is consequently desirable into how students identify patterns when working with problems in functional contexts and the relationship between the patterns identified in specific values and their ability to generalize. Thus, a future line of research could be focused on interviewing students to obtain more evidence about their ideas working with functional thinking s.

\section{References}

Ayala-Altamirano, C., \& Molina, M. (2019). Meanings attributed to letters in functional contexts by primary school students. International Journal of Science and Mathematics Education, 18(7), 1271-1291.

Ayalon, M., Watson, A., \& Lerman, S. (2015). Functions represented as linear sequential data: relationships between presentation and student responses. Educational Studies in Mathematics, 90(3), 321-339.

Blanton, M. L., Brizuela, B. M., Gardiner, A., Sawrey, K., \& Newman-Owens, A. (2015). A learning trajectory in 6-year-olds' thinking about generalizing functional relationships. Journal for Research in Mathematics Education, 46(5), 511-558.

Blanton, M. L., Levi, L., Crites, T., \& Dougherty, B. J. (2011). Developing essential understanding of algebraic thinking for teaching mathematics in grades 3-5. Reston, VA: NCTM.

Brizuela, B., \& Earnest, D. (2008). Multiple notational systems and algebraic understanding: The case of the "best deal" problem. In J. J. Kaput, D. W. Carraher, \& M. L. Blanton (Eds.), Algebra in the early grades (pp. 273-302). New York, NY: LEA.

Bush, S. B., \& Karp, K. S. (2013). Prerequisite algebra skills and associated misconceptions of middle grade students: A review. The Journal of Mathematical Behavior, 32(3), 613632.

Cai, J. (2005). US and Chinese teachers' constructing, knowing and evaluating representations to teach mathematics. Mathematical Thinking and Learning, 7(2), 135169.

Cai, J., \& Knuth, E. (2005). Introduction: The development of students' algebraic thinking in earlier grades from curricular, instructional and learning perspectives. $Z D M, 37(1), 1-4$. 
Cañadas, M. C., \& Castro, E. (2007). A proposal of categorisation for analysing inductive reasoning. $P N A, 1(2), 67-78$.

Cañadas, M. C., Brizuela, B. M., \& Blanton, M. L. (2016). Second graders articulating ideas about linear functional relationships. The Journal of Mathematical Behavior, 41, 87-103.

Carpenter, T. P., \& Franke, M. (2001). Developing algebraic reasoning in the elementary school: generalisation and proof. In H. Chick, K. Stacey, J. Vincent, \& J. Vincent (Eds.), The future of the teaching and learning of algebra. Proceedings of the 12th ICMI study conference (Vol 1, pp. 155-162). Melbourne, Australia: ICMI.

Carraher, D. W., \& Schliemann, A. (2007). Early algebra and algebraic reasoning. In F. Lester (Ed.), Second handbook of research on mathematics teaching and learning (pp. 669-705). Reston, VA: NCTM.

Carraher, D. W., Schliemann, A. D, \& Schwartz, J. L. (2008). Early algebra is not the same as algebra early. In J. J. Kaput, D. W. Carraher, \& M. L. Blanton (Eds.), Algebra in the early grades (pp. 235-72). New York, NY: LEA.

Confrey, J., \& Smith, E. (1994). Exponential functions, rates of change, and the multiplicative unit. Educational Studies in Mathematics, 26(2-3), 135-164.

Dienes, Z. P. (1961). On abstraction and generalisation. Harvard Educational Review, 31(3), 281-301.

Kaput, J. J. (1991). Notations and representations as mediators of constructive processes. In E. V. Glasersfeld (Ed.), Radical constructivism in mathematics education (pp. 53-74). Dordrecht, The Netherlands: Springer.

Kaput, J. J. (2008). What is algebra? What is algebraic reasoning? In J. Kaput, D. Carraher, \& M. Blanton (Eds.), Algebra in the early grades (pp. 5-17). New York, NY: LEA.

Kelly, A. E., \& Lesh, R. A. (2000). Research design in mathematics and science education. New Jersey, NY: Lawrence Erlbaum Associates.

Kieran, C., Pang, J., Schifter, D., \& Fong, S. (2016). Early algebra. Research into its nature, its learning, its teaching. New York, NY: Springer.

Küchemann, D. (1981). Algebra. In K. Hart (Ed.), Children's understanding of mathematics: 11- 16 (pp. 102-119). London, United Kingdom: John Murray.

Kuckartz, U. (2019). Qualitative text analysis: A systematic approach. In G. Kaiser \& N. Presmeg (Eds.), Compendium for early career researchers in Mathematics Education (pp. 181-198). Cham, Switzerland: Springer. 
Lins, R., \& Kaput, J. (2004). The early development of algebraic reasoning: The current state of the field. In K. Stacey, H. Chick, \& M. Kendal (Eds.), The future of the teaching and learning of algebra: The 12th ICMI study (pp. 47-70). Norwell, MA: Kluwer.

Mason, J. (1996). Expressing generality and roots of algebra. In B. Bednarz, C. Kieran, \& L. Lee (Eds.), Approaches to algebra (pp. 65-86). Dordrecht, The Netherlands: Kluwer.

Mason, J. H., Grahamn, A., Pimm, D., \& Gowar, N. (1985). Routes to/Roots of algebra. East Kilbride, United Kingdom: The Open University Press.

Morales, R., Cañadas, M. C., Brizuela, B. M., \& Gómez, P. (2018). Relaciones funcionales y estrategias de alumnos de primero de educación primaria en un contexto funcional [Functional relationships and strategies of first graders in a functional context]. Enseñanza de las Ciencias, 36(3), 59-78.

Panorkau, N., \& Maloney, A. (2016). Early algebra: Expressing covariation and correspondence. Teaching Children Mathematics, 23(2), 90-99.

Pinto, E., \& Cañadas, M. C. (2018). Generalization in fifth graders within a functional approach. $P N A, 12(3), 173-184$.

Pinto, E., \& Cañadas, M. C. (2021). Generalization of third and fifth graders from a functional approach to early algebra. Mathematics Education Research Journal, 33, 113134.

Radford, L. (2018). The emergence of symbolic algebraic thinking in primary school. In C. Kieran (Ed.), Teaching and Learning Algebraic Thinking with 5- to 12-years-olds (pp. 325). Cham, Germany: Springer.

Rivera, F. (2013). Teaching and learning patterns in school mathematics. Psychological and pedagogical considerations. New York, NY: Springer.

Romberg, T., Fennema, E, \& Carpenter, T. (1993). Integrating research on the graphical representation of functions. New York, NY: Routledge.

Schhreier, M. (2012). Qualitative content analysus in practice. London, United Kingdom: Sage.

Sfard, A. (1991). On the dual nature of mathematical conceptions: Reflections on processes and objects as different sides of the same coin. Educational Studies in Mathematics, 22(1), 1-36.

Smith, E. (2003). Stasis and change: Integrating patterns, functions, and algebra throughout the K-12 curriculum. In J. Kilpatrick, W. G. Martin, \& D. Schifter (Eds.), A research 
companion to principles and standards for school mathematics (pp. 136-150). Reston, VA: NCTM.

Smith, E. (2008). Representational thinking as a framework for introducing functions in the elementary curriculum. In J. J. Kaput, D. W. Carraher, \& M. L. Blanton (Eds.), Algebra in the early grades (pp. 133-163). New York, NY: LEA.

Stephens, A. C., Ellis, A. B., Blanton, M. L., \& Brizuela, B. M. (2017). Algebraic thinking in the elementary and middle grades. In J. Cai (Ed.), Compendium for research in mathematics education (pp. 386-420). Reston, VA: NCTM.

Vinner, S., \& Dreyfus, T. (1989). Images and definitions for the concept of function. Journal for Research in Mathematics Education, 20(4), 356-366.

Warren, E., Miller, J., \& Cooper, T. J. (2013). Exploring young students' functional thinking. PNA, 7(2), 75-84.

Wilkie, K. J. (2016). Students' use of variables and multiple representations in generalizing functional relationships prior to secondary school. Educational Studies in Mathematics, 93(3), 333-361.

Williams, S. R. (1993). Mathematics and being in the world: Toward an interpretative framework. For the Learning of Mathematics, 13(2), 2-7.

Yerushalmy, J., \& Schwartz, J. (1993). Seizing the opportunity to make algebra mathematically and pedagogically interesting. In T. A. Romberg, E. Fennema, \& T. P. Carpenter (Eds.), Integrating research on the graphical representation of function (pp. 41-68). New York, NY: Routledge. 